* Cómo citar este artículo: Leonardo-Loayza, R. A. (2020). Maternidades proscritas, mandatos sociales y violencia en la novela $L a$ perra, de Pilar Quintana. Estudios de Literatura Colombiana 47,pp. 151-168. DOI: https://doi. org/10.17533/udea.elc.n47a08

1 https://orcid.org/0000-0001-6867-2127 rleonardol@unmsm.edu.pe

Universidad Nacional Mayor de San Marcos, Perú
Editores: Andrés Vergara Aguirre, Christian Benavides Martínez, Valentina Noreña Gómez

Recibido: 15.02 .2020

Aprobado: 27.04.2020

Publicado: 23.06.2020

Copyright: $\odot 2020$ Estudios de Literatura Colombiana. Este es un artículo de acceso abierto distribuido bajo los términos de la Licencia Creative Commons AtribuciónNo comercial - Compartir igual 4.0 Internacional

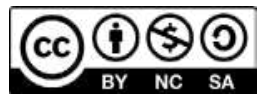

\section{MATERNIDADES PROSCRITAS, MANDATOS SOCIALES Y VIOLENCIA en la novela La PerRa, de Pilar QUINTANA*}

\author{
OUTLAWED MATERNITY, SOCIAL MANDATES \\ AND VIOLENCE IN THE NOVEL LA PERRA, BY \\ Pilar Quintana
}

Richard Angelo Leonardo-Loayza ${ }^{1}$

Resumen: este artículo analiza la representación de la maternidad en La Perra (2017) de Pilar Quintana. La hipótesis apunta a que en esta novela se produce un desmantelamiento de los mandatos sociales a los que están sometidas las mujeres que desean ser consideradas auténticas madres. Dichos mandatos son opresivos para ellas, más aún si se actualizan en contextos de pobreza, lo que genera en las mujeres reacciones extremas, entre las que se destacan el surgimiento de la violencia. El estudio se realiza a partir de los aportes teóricos de Adrienne Rich, Cristina Palomar, Massimo Recalcati, Jacqueline Rose, Orna Donath, Judith Butler y Byung-Chul Han.

Palabras clave: Pilar Quintana; La perra; maternidad; mandatos sociales; violencia.

\begin{abstract}
In this article, we analyze the representation of motherhood in La Perra (2017) by Pilar Quintana. Our hypothesis assumes that, in this novel, there is an operation to dismantle the social mandates to which women are subjected if they wish to be considered authentic mothers. These mandates are oppressive for them, even worse if they are updated in contexts of poverty that generate extreme reactions in women, among which the emergence of violence can be recognized. We conduct our study based on the theoretical contributions of Adrienne Rich, Cristina Palomar, Massimo Recalcati, Jacqueline Rose, Orna Donath, Judith Butler and Byung-Chul Han.
\end{abstract}

Keywords: Pilar Quintana; La perra; maternity; social mandates; violence. 
A pesar de constituir un acontecimiento fundamental para el ser humano, "la fuente y el origen de nuestro ser en el mundo" (Rose, 2018, p. 39), la representación de la maternidad fue escasamente abordada en la literatura. Una explicación de este descuido puede ser el hecho de que los creadores de las ficciones eran principalmente varones y, por lo tanto, extraños a las diversas cuestiones que implican la experiencia de ser madre (Reyes, 2017, p. 2). Asimismo, podría ensayarse como una razón complementaria a dicha explicación el factor de que tales escritores varones no le reconocían un auténtico valor literario a este tipo de prácticas; es decir, que desde una percepción androcéntrica de la realidad, escribir algo referido a la maternidad no alcanzaba el estatus de un "verdadero" tema literario. Sin embargo, en estas últimas décadas el contexto ha cambiado considerablemente, ya sea porque cada vez es más prolífica la presencia de mujeres que ejercitan la literatura, o debido a que el tema de la maternidad, gracias a los discursos feministas y posfeministas, se ha convertido en una preocupación central de los debates teóricos contemporáneos. El caso concreto es que la literatura presenta al día de hoy una especie de auge por narrar la experiencia de ser madre y todas las implicancias que se derivan de tal condición.

Dichas narraciones no solo abordan el tema de la maternidad desde una perspectiva tradicional, en la que se representa el amor materno como algo instintivo, incondicional, una manifestación esencial de toda mujer desde su infancia; también es presentado desde una óptica que asume la maternidad como una construcción social y cultural, en la que la mujer está a merced de una serie de mandatos sociales que, además de someterla, terminan por violentar su propia identidad. En otras palabras, la literatura está representando a las madres como seres predestinados a realizar esta función, seguras de sí mismas, abnegadas y repletas de bondades, pero también como individuos conflictuados, extraviados en medio de exigencias que no acaban de entender y que se les hace imposible de cumplir a cabalidad. Ahora bien, en la narrativa latinoamericana reciente se puede apreciar la aparición de un conjunto importante de autoras,que adoptan este segundo paradigma y escriben sobre las dificultades reales que implica asumir la maternidad. Por citar solo a algunas de ellas, tenemos a las mexicanas Valeria Luiselli, Los ingrávidos (2011), Patricia Laurent Kullick, La giganta (2015), y Brenda Navarro, Casas vacias (2017); las colombianas Margarita García Robayo, Tiempo muerto (2017), y Pilar Quintana, La perra (2017); la argentina Claudia Piñeiro, Una suerte pequeña (2015), y a 
la ecuatoriana Mónica Ojeda con su novela Mandíbula (2018). Un denominador común en las ficciones de estas autoras es que presentan la emergencia de la representación de un nuevo sujeto social, la "mala madre", un personaje que se define como alguien cuyos actos no se inscriben en los patrones tradicionales de la maternidad occidental.

Este artículo analizará La perra, novela de Pilar Quintana (Cali, 1972). En dicha obra, Quintana desmonta la noción tradicional de maternidad a la que la sociedad estaba acostumbrada, y señala, además, la realidad que permea el deseo de ser madre en un contexto de desigualdad social. Para ello, al realizar esta lectura crítica se apelará a los aportes de Adrienne Rich, Massimo Recalcati, Jacqueline Rose, Orna Donath, Judith Butler y Byung-Chul Han, entre otros.

\section{De buenas y malas madres o las trampas de la maternidad}

La antropóloga Marcela Lagarde (1997) explica que "El género es la categoría correspondiente al orden sociocultural configurado sobre la base de la sexualidad: la sexualidad a su vez definida y significada históricamente por el orden genérico" (p. 26). El género es una construcción social que, en función a la diferencia entre hombres y mujeres, asigna una serie de roles que se espera que las mujeres y los varones cumplan para ser reconocidos como tales. Tale roles de género se manifiestan mediante mandatos que proveen reglas y normas sociales que dictaminan los modos de actuar de los hombres y las mujeres. Por ejemplo, mientras los primeros deben ser racionales, fuertes, protectores, agresivos, intrépidos y autónomos, de las segundas se espera que sean sensibles, maternales, cuidadoras, sumisas, complacientes, dependientes. Debe señalarse que estos mandatos genéricos están inscritos en el orden simbólico, adquiriendo el carácter prescriptivo que asegura su reproducción (Ibarlucía, 2009, p. 287).

Bajo este sistema, la maternidad constituye un mandato clave de la femineidad, y a su vez se convierte en una condición que exige sus propios mandatos; es decir, las mujeres, cuando llegan a procrear, cargan con un conjunto de prescripciones que están sujetas a efectuar si quieren ser reconocidas como madres. En cada época se ha construido una serie de maneras de entender la maternidad y el rol materno, lo que se espera de las madres, aquello que se valora como correcto e incorrecto en el ejercicio de la maternidad. Los atributos vinculados a dicha condición la caracterizan por ser algo natural, esencial 
e instintivo de las mujeres. Tal concepción se reproduce en la esfera de lo privado, de lo doméstico, resaltando las capacidades femeninas en cuanto a la reproducción y a los cuidados. De este modo, la división sexual del trabajo establece que las mujeres, además de la concepción, la gestación, el parto y la lactancia, deben ocuparse en forma exclusiva de la crianza de los hijos, porque poseen "una especie de caja de herramientas innata que induce a las mujeres más que a los hombres a criar a sus hijos, ya sean biológicos o adoptados, y a cuidar de ellos" (Donath, 2017, p. 59). Desde esta lógica, propia del sistema patriarcal, se establece la idea de que ser madres es el destino natural de las mujeres, aunque perpetúe situaciones de desigualdad social, política y económica entre ellas y los hombres. Cristina Palomar (2004) lo resume en los siguientes términos:

El proceso de construcción social de la maternidad supone la generación de una serie de mandatos relativos al ejercicio de la maternidad encarnados en los sujetos y en las instituciones, y reproducidos por los discursos, las imágenes y las representaciones que producen, de esta manera, un complejo imaginario maternal basado en una idea esencialista respecto a la práctica de la maternidad. Como todos los esencialismos, dicho imaginario es transhistórico y transcultural, y se conecta con argumentos biologicistas y mitológicos. De aquí es donde se desprende la producción de estereotipos, de juicios y de calificativos que se dirigen a aquellas mujeres que tienen hijas o hijos y que estas mismas autoaplican (p. iб).

Se puede apreciar, entonces, que el ser madre conlleva una serie de estereotipos que se manifiestan como una representación ideal y abstracta, que encarna la esencia atribuida a la maternidad. De esta manera, la madre es portadora "del amor sin límites" (Recalcati, 2018, p. 130) y el instinto materno, del cual se derivan virtudes como la paciencia, el cuidado, la tolerancia, la protección, el sacrificio y la entrega gustosa de las mujeres a la maternidad. Del cumplimiento o no de estos mandatos surgen dos estereotipos: las buenas y las malas madres. Respecto a las primeras, Ricardo Garay (2008) explica que estos estereotipos

[...] no se reducen a esta prescripción sino que las normas incluyen además una serie de prohibiciones en torno a los defectos a eliminar: el egoísmo, el erotismo, la hostilidad y el no dejar transparentar sus ansiedades, necesidades y deseos [...]. El ideal maternal abarca no solo los comportamientos a tener, sino también los sentimientos que se deben vivenciar. El ideal maternal es la interiorización de todos estos preceptos y prescripciones que normativizan la experiencia de la maternidad (p. 32). 
Es así que el comportamiento de las madres no solo está supeditado a las acciones por realizar en favor de sus hijos (en el que se supone se antepone a estos sobre sí mismas), sino del control de los afectos y sentimientos que les prodigan. Como puede apreciarse, estos mandatos también regulan el mundo emocional de las madres, reglamentando aquello que es o no apropiado para ellas. De alguna manera - aunque como dice Orna Donath (2017), no existe "una única emoción que los hijos inspiren" (p.63)—, el imaginario social asume y espera que todas las madres sientan lo mismo si desean ser vistas como "buenas madres". Se exige que estas se sacrifiquen por los hijos, los cuiden, y que además los quieran a todos sin objeción ni condición alguna. Un aspecto importante para tener en cuenta es que estas regulaciones sociales, plasmadas en el imaginario colectivo, no solo se producen de parte de la sociedad, representada en el resto de la gente, sino que está interiorizado en las propias madres. Esto en la esperanza de que se cumplan las promesas que, desde siempre, les ha formulado el sistema patriarcal. Donath (2017) lo explica del siguiente modo:

La maternidad la conducirá a una existencia valiosa y justificada, un estado que corrobora su necesidad y vitalidad. La maternidad anunciará tanto al mundo como a sí misma su extensión de mujer en toda la extensión de la palabra, una figura moral que no solo paga su deuda con la naturaleza al crear vida, sino que además la protege y la promueve ( $\mathrm{p}$. 34).

Cabe preguntarse si todas las mujeres están predispuestas a ser "buenas madres", o mejor, si todas ellas poseen las condiciones materiales y emocionales para lograr tal ideal. Lo cierto es que existe una gran cantidad de mujeres que no desean, o no pueden lidiar con tales exigencias, ya que son difíciles y, muchas veces, imposibles de alcanzar. Bajo este contexto aparece la figura de la "mala madre". Palomar (2004) define dicha categoría con los siguientes términos:

La categoría de "malas madres" es el negativo de la construcción social de la maternidad en nuestro medio. Esta categoría, por lo tanto, es el resultado del contraste que se establece con el ideal de género fabricado culturalmente para crear el mito de la mujer-madre, basado en la creencia, en el instinto materno, en el amor materno y en el sacrificio y la entrega gustosa de las mujeres a la maternidad. Visto así, las "malas madres" son aquellas mujeres que no cumplen con los ideales de la maternidad socialmente construida con base en tres campos fundamentales: el legal, el moral y el de la salud. Las "buenas madres", por contraste, son aquellas que se ajustan a dichos ideales (p. 19). 
Si bien las "malas madres" siempre han estado presentes en la historia de la humanidad, lo cierto es que recién se ha empezado a reflexionar seriamente sobre ellas, no en un afán de estigmatizarlas o proscribirlas, sino con el ánimo de comprender la complejidad de su existencia. En esta línea de sentido, se entiende por qué estas "malas madres" se han convertido en protagonistas de una importante parcela de la narrativa latinoamericana que se escribe por estos días. No son el resultado de una moda; más bien surgen como el testimonio de la presencia de un sujeto social marginalizado y rechazado por el mismo sistema que lo ha producido: el sistema patriarcal.

\section{De maternidades protésicas a maternidades proscritas}

En La perra, obra que aborda el tema de la maternidad, pone en evidencia los efectos posibles que se pueden generar a raíz de los mandatos sociales a los que están sometidas las mujeres cuando desean ser madres. En la novela se presenta el caso de Damaris, mujer afrodescendiente y pobre, quien vive con Rogelio desde que cumplió la mayoría de edad. Tras un par de años de convivencia sin que puedan tener hijos, la gente empezó a insistirles: “¿Para cuándo los bebés?’ O ‘Qui’hubo que se están demorando"' (Quintana, 2019, p. 18). A partir de esta situación, Damaris comenzó a beber infusiones de hierbas que le recomendan para la fertilidad. Sin embargo, dichas bebidas no surtieron el efecto deseado. Así, "Pasaron otros dos años más y ya tuvieron que explicarles a los que preguntaban que el problema era que ella no quedaba embarazada. La gente empezó a evitar el tema y la tía Gilma le aconsejó que fuera a ver a Santos” (p. 20), la curandera. En el imaginario social, que definitivamente es un imaginario patriarcal, se piensa que cuando dos personas se unen lo lógico es que tengan hijos. Cuando esa situación no se produce, la comunidad interviene, ya sea a través de las constantes preguntas como las que le efectuaban a Damaris o los consejos de la tía Gilma. Resulta interesante notar que también en este imaginario, lo primero que se asume es que la mujer es la responsable directa de la no concepción de los hijos. En cambio, se da por descontado que el varón es fértil y potente.

A casusa del desengaño de las hierbas, Damaris sigue el consejo de la tía Gilma y va a buscar a Santos, quien 
Conocía de hierbas, sabía sobar y curaba con secreto, es decir, invocando palabras y rezos. A Damaris le hizo un poco de cada cosa y cuando vio que fracasaba le dijo que el problema debía ser el marido y lo mandó a llamar. Aunque se notaba incómodo, Rogelio se tomó todos los bebedizos, aceptó todos los rezos y soportó todas las friegas que le hizo Santos, pero entre más tiempo pasaba sin que se produjera el embarazo más reacio se ponía y un día anunció que ya no iría más. Damaris lo tomó como un ataque en contra de ella y le dejó de hablar (pp. 20-21).

En este fragmento se corrobora la idea imperante según la cual la mujer es sindicada como la primera responsable de la esterilidad. Una cuestión importante que se debe resaltar es que el principal interés por tener descendencia habita en Damaris, no en Rogelio. Lo anterior se explica porque en la división sexual del trabajo, es a la mujer a quien le corresponde gestionar esta acción propia de las familias (un matrimonio sin hijos no se considera una familia "verdadera"). En ese sentido, se entiende la actitud de Damaris cuando Rogelio se cansa de intentarlo. Para ella es una afrenta personal, ya que el hecho de no tener hijos pone en duda su femineidad. En otras palabras, no poder tener hijos la define como menos mujer que aquellas que sí pueden procrear. La maternidad es una condición que reafirma la femineidad de las mujeres, que las completa. No alcanzar dicho estado sugiere un defecto, que son imperfectas. De este modo, las mujeres experimentan un detrimento en su autoestima. Damaris se siente así, ya que a lo largo del relato manifiesta un descontento consigo misma:

\begin{abstract}
A Damaris la cubrió la tristeza y todo - levantarse de la cama, preparar la comida, masticar los alimentos - le costaba un trabajo enorme. Sentía que la vida era como una caleta y que a ella le había tocado atravesarla caminando con los pies enterrados en el barro y el agua hasta la cintura, sola, completamente sola, en un cuerpo que no le daba hijos y que solo servía para romper cosas ( $\mathrm{p} .75)$.
\end{abstract}

Damaris considera que su vida no está completa y reacciona en contra de sí misma, culpándose por la circunstancia de no poder tener hijos. Esta mujer se percibe como un ser imperfecto, torpe, con un cuerpo cuya utilidad es definida en función a su capacidad de procrear. ${ }^{1}$ En el pensamiento de esta mujer, el cuerpo de ella solo adquiere sentido para la

1 Judith Butler explica que el cuerpo es un ideal construido por medio de prácticas reguladas histórica y socialmente, pues en él se alojan los mensajes y los condicionamientos socioculturales (1997). A las mujeres se les ha enseñado que la misión primordial de sus cuerpos es servir de receptáculo para el ejercicio de la maternidad. 
reproducción. En un pasaje de la novela, ocurre un hecho singular referido a este aspecto: a Damaris se le resbalaron unas tazas que Rogelio había comprado hacia poco y este le dijo:

- Ni dos meses te duraron [...] Vos sí tenés la mano pesada.

Damaris no le contestó, pero esa noche, cuando apagaron el televisor y él intentó acercarse, ella le hizo el quite y se metió al cuarto donde dormía sola. Se estuvo mirando las manos durante un rato. Las tenía inmensas, con los dedos anchos, las palmas curtidas y resecas y las líneas tan marcadas como grietas en la tierra. Eran manos de hombre, las manos de un obrero de construcción o un pescador capaz de jalar pescados gigantes (pp. $58-59$ ).

Debe ponerse atención en la percepción que tiene Damaris sobre su cuerpo, en este caso, de sus manos. Son "inmensas", con "dedos anchos", "palmas curtidas y resecas" y "líneas como grietas en la tierra". En otros términos, no corresponden a las manos de una mujer. Por eso, se afirma que son las manos de un hombre, de un obrero de construcción o un pescador. No es el narrador el que está focalizando las manos, sino la propia Damaris, es ella quien asume y valora que sus manos son masculinas. El subtexto de esta declaración es que ella no se considera una mujer auténtica, con las cualidades físicas que supuestamente toda mujer debería poseer: delicadeza, finura, habilidad. En el fondo, esta representación que hace sobre sí misma es la ratificación de que no puede ser una madre, porque su cuerpo no es femenino, no está preparado para merecer la maternidad.

Después de que no funcionaran los artificios de Santos, la tía Gilma le habló a Damaris de una mujer de treintaiocho años (Damaris ya tenía 30) que quedó embarazada gracias a los menesteres del jabainá, un médico indígena al que acudió, y quien no solo le dio más bebedizos, sino que le sumó baños, sahumerios y la invitó a ceremonias en las que la ungió, frotó, fumó, rezó y cantó. Pero no lograron nada:

Damaris no tuvo siquiera un atraso y el jabainá les dijo que no podía hacer nada por ellos. De alguna forma fue un alivio, pues tener relaciones se había convertido en una obligación. Dejaron de tenerlas, al principio tal vez solo para descansar, y ella se sintió liberada, pero al mismo tiempo derrotada e inútil, una vergüenza como mujer, una piltrafa de la naturaleza (Quintana, 2019, p. 24).

Aquí caben dos cuestiones para reflexionar. La primera es que Damaris deja de tener relaciones sexuales con su esposo Rogelio. Una vez que pierde toda esperanza de 
quedar embarazada, considera que el sexo no tiene importancia si no conlleva a la reproducción. De algún modo, el deseo postergado de ser madre silencia otro tipo de deseos, como tener relaciones con su marido, lo que se ha convertido en una carga. En esta línea de interpretación, se puede entender por qué para ella significó una liberación la suspensión de las relaciones sexuales. De otra parte, es revelador el hecho de que se reafirme este sentimiento de culpabilidad por no poder tener hijos. Damaris no solo se siente derrotada e inútil (que no sirve), sino que es una "vergüenza como mujer”, porque no puede cumplir con el rol que le ha encomendado la naturaleza, por eso lo de "piltrafa" (residuo) de esta. Aquí se observa la poderosa relación que la sociedad, desde el origen de los tiempos, ha establecido entre mujer y naturaleza, considerándola, como dice bien Sherry B. Ortner (1979), más próxima que la que pueda surgir con el hombre, debido a las funciones fisiológicas de la mujer; "una concepción con la que ella misma, en cuanto observadora de sí y del mundo, puede estar de acuerdo"(Ortner, 1979, p. 119). La mujer es concebida como una metonimia de la naturaleza, pues ella, como esta, puede y debe dar vida.

Ahora bien, las cosas cambian cuando en una de las caminatas por el pueblo, Damaris encuentra a su vecina doña Elodia, parada en medio de la calle y con una caja de cartón conteniendo cachorros. Doña Elodia le cuenta que le envenenaron a su perra y que está regalando sus crías. Damaris se conmueve y decide llevarse una de ellas. Doña Elodia le advierte que se trata de una hembra, pero a Damaris no le importa e igual se la lleva. En el imaginario social, un cachorro hembra no tiene el mismo valor que uno macho, por eso la necesidad de advertirle de su condición a Damaris. Está claro que este rechazo tiene su fundamento en que las hembras son propensas a la maternidad, la cual es percibida como un problema (económico, si se piensa en la manutención de su potencial descendencia). Algo similar sucede con las mujeres (que también son hembras), porque cuando llegan a la maternidad esta es estimada como un tipo de enfermedad o forma de debilitamiento (Rose, 2018, p. 36). Esta es una de las contradicciones del sistema patriarcal, que le exige a las mujeres convertirse en madres, y en cuanto lo logran, el propio sistema las evalúa como una carga social.

Volviendo al relato, a partir de ese momento Damaris establecerá una relación especial con la perra adoptada, la cual se convertirá en un remedio para su soledad. Por ejemplo, como no sabía dónde llevar a la cachorra, "se la puso contra el pecho. Le 
cabía en las manos, olía a leche y le hacía sentir unas ganas muy grandes de abrazarla y llorar"(Quintana, 2019,p. 11). Desde el principio, Damaris no mira a este animalito como una mascota. No es gratuito que se lo ponga contra el pecho (símbolo supremo de la maternidad), sino que este acto recuerda lo que hacen las madres en cuanto pueden ver a sus hijos recién nacidos. Esta impresión se refuerza con la ternura que le provoca entrar en contacto con la cachorra; al tocarla, nace en Damaris un deseo de protegerla, como si fuera un hijo. Massimo Recalcati (2018) nos dice que "el Otro materno es el primer 'socorredor' en el arranque traumático de la vida; sus manos sirven para preservar esa vida, para protegerla, para sustraerla a la posibilidad de la caída” (p. 23). Esta apreciación se reafirma con el hecho de que Damaris, a pesar de saber el mal carácter de su esposo con respecto a los animales (tiene tres perros y los maltrata), de igual modo se lleva a la cachorra a su casa: "se dijo que con la perra todo sería diferente. Era suya y ella no permitiría que Rogelio le hiciera ninguna de esas cosas, no dejaría que la mirara mal" (Quintana, 2019, p. 13). Damaris se siente en la obligación no solo de querer, sino de proteger a su perra, incluso de su pareja.

Ella tendrá dificultades para alimentar a su cachorra. Al inicio compró una jeringa para darle leche, porque el perro no sabía lamer de un tazón y los teteros que vendían en el pueblo eran para bebés humanos y muy grandes. Don Jaime, el dueño de la tienda del pueblo, le recomendó que la alimentara con un gotero, pero Damaris se dio cuenta de que esto no funcionaba. Un día se le ocurrió remojar pan con leche y dejar que la perra lo chupara, y esa fue la solución. Damaris no se rinde ante el primer escollo que encuentra, sino que se las ingenia para alimentar a su cachorra a toda costa. Así cumple con uno de los mandatos de la maternidad: alimentar a su hijo. Un aspecto interesante que se debe destacar es el enorme esfuerzo que realiza Damaris para alimentar regularmente a su perra. En el relato leemos:

En esos días la marea estaba alta de mañana, así que para comprar el pan de la perra Damaris tenía que levantarse a primera hora, cargar el canalete desde la cabaña, bajar las escaleras con él al hombro, empujar el potrillo desde el embarcadero, meterlo al agua, canaletear hasta el otro lado, amarrar el potrillo a una palma, llevar el canalete hasta la casa de alguno de los pescadores que vivían junto a la calera, pedirle al pescador, su mujer o los niños que se lo cuidaran, oírle las quejas y los cuentos al vecino y atravesar medio pueblo caminando hasta la tienda de don Jaime... y lo mismo de vuelta. Todos los días, aún bajo la lluvia (p. ıб). 
Como se puede apreciar, no se trata de una tarea fácil traer el alimento para el perro, todo lo contrario, demanda mucho trabajo. Sin embargo, aquello no le interesa a Damaris con tal de poder cumplir con el mandato de sacrificarse por su perra, a la cual debe cuidar. Esta actitud se remarca si se analiza el trato que le da a su cachorra respecto a los otros perros que hay en su casa. Rogelio tiene tres más: Danger, Olivo y Mosco. Con la perra hay una distinción: "Durante el día Damaris llevaba metida a la perra en el brasier, entre sus tetas blandas y generosas, para mantenerla calientita. Por las noches la dejaba en la caja de cartón que le había regalado don Jaime, con una botella de agua caliente y la camiseta que había usado ese día para que no extrañara su olor" (p. 16). Este comportamiento va más allá de un simple acto de piedad hacia los animales. El trato que le procura a su perra, lejos de ser el que se brinda a un cachorro, se asemeja más a la crianza de un ser humano. Tal situación llega a su manifestación más extrema cuando Damaris decide ponerle un nombre a la perra. La llamará Chirli. En una ocasión, cuando la visitó su prima Luzmila, con quien había crecido y se conocían todo, esta le preguntó al escuchar el nombre de la cachorra: "—¿Chirli como la reina de belleza? — se rio Luzmila—, ¿así no era que le ibas a poner a tu hija?” (Quintana, 2019, p. 19). Este hecho resulta altamente significativo. Ponerle al perro el nombre que había elegido para la hija que deseaba tener implica una acción de sustitución, es decir, con su accionar Damaris pone a la perra en el lugar de la hija no procreada. A nivel simbólico, le está reconociendo un valor similar o igual, de ahí las demostraciones de afecto tan intensas. Debe recordarse que el nombre es algo que existe antes de la procreación y, como explican Marcer y Kicillof (1990), es por este empeño en nombrar que el nombre que se ha elegido estará cargado de una fuerza inconsciente que buscará hacer realidad un ideal o un deseo que ha sido postergado, pues va a estar relacionado con el material inconsciente. Asimismo, cuando se recibe un nombre, "se recibe también una carga simbólica de lo que se espera que sea, así que puede identificarse con estas depositaciones para así llegar a ser eso que en realidad no es ciertamente" (Ledezma, 2016, p. 35). Y Damaris, con la decisión de adoptar a Chirli y tratarla de esa manera, ha hecho realidad su deseo pospuesto de ser madre. La perra se ha convertido en su hija, a pesar de no haberla parido ni tratarse de un ser humano.

Hay en esta acción de Damaris un desacato a aquello que Adrienne Rich (2019) llamó "la institución de la maternidad", es decir, la "maternidad bajo el patriarcado: el conjunto de suposiciones y normas, de reglamentos y controles que secuestra la 
experiencia, y la ordena de acuerdo a un poder ajeno y domestica esa parcela de la vida de millones de mujeres (y otras entidades que gestan)" (p. 18). Con este acto de adopción que realiza Damaris con Chirli, se produce una resignificación del concepto de maternidad, el cual es desbordado, cuestionado y redimensionado en su alcance. La maternidad ya no es vista como una imposición biológica, que provenga de la naturaleza, sino como una decisión humana, que abarca elegir el tipo de prole que se desea, así esta no sea humana. Por este motivo, puede decirse que no se está ante la presencia de una mujer que acepta pasivamente los dictados del destino, que le ha negado rotundamente la maternidad, sino ante un ser con agencia, que ha hecho algo para superar su estado de precariedad y lograr sus metas (Sen, 1985, p. 203). Pero resulta necesario señalar que dicho acto no está libre de ciertas circunstancias que posibilitan y empujan su ocurrencia. Tanto Damaris como Rogelio son gente de escasos recursos económicos. Viven de la pesca artesanal y de lo que logren ganar por mantener algunas casas de verano de la gente pudiente que reside en la ciudad. Además, habitan en un pueblo (de una sola calle) del Pacífico colombiano, entre el mar y la montaña, sin un acceso real a la modernidad (si bien sufren sus consecuencias, no pueden acceder a sus supuestas bondades). Por esta razón, es inimaginable pensar en algún método de reproducción asistida, que les pueda ayudar en la concepción de su hijo, solo les quedan las hierbas, los bebedizos, los rezos y los curanderos. En ese contexto, otra posibilidad negada es la adopción de un niño. Es así como el único camino que encuentra Damaris para convertirse en madre es adoptar a esta cachorra, la cual fungirá como la hija negada por la naturaleza. Este caso podría definirse como una maternidad protésica, en la que el hijo (para ser exactos, la hija no procreada) es reemplazado, sustituido, por otra entidad similar: una perra.

Ahora bien, Chirli crece rápidamente y, a medida que lo hace, se convierte en un ser más autónomo e independiente. Por ejemplo, ha adquirido la costumbre de escaparse e internarse en el monte, en el cual pasa días enteros. Damaris percibe esta conducta de forma negativa, porque asume que su perra es desobediente, rebelde y de algún modo la está abandonando. Por esta razón, intenta escarmentarla de diferentes maneras, pero no obtiene ningún resultado positivo. En una de las escapadas de la perra, Damaris cambia ostensiblemente de actitud respecto a ella:

[...] quitó la cama del quiosco y la tiró por el acantilado hacia un basurero de tarros de aceite de motor y barriles de gasolina rotos que había en la caleta. Dejó 
de acariciarla, de apartarle las mejores sobras, de hacerle caso cuando le movía la cola, de despedirse de ella por las noches y hasta de prenderle la luz del quiosco. Cuando la mordió un chimbilaco, Damaris solo se dio cuenta porque Rogelio le hizo notar el reguero de sangre y le preguntó si no pensaba curarla. El corte era en la nariz y no paraba de sangrar. Como Damaris se encogió de hombros y siguió en lo que estaba, colando el café de la mañana, Rogelio se fue a buscar el Gusantrex a la cabaña y se lo aplicó él mismo (Quintana, 2019, p. 73).

Damaris le ha quitado lo material a su perra: el cobijo, la comida, la luz del quiosco para que no la muerdan los murciélagos. Asimismo, lo afectivo: ya no la acaricia, ni tiene gestos de amor hacia ella como el despedirse todas las noches o ver que se encuentre bien. Es muy significativo que, ante la mordedura que recibe Chirli de los chimbilacos, ella no se sienta afectada y delegue en su esposo la acción de cuidarla. Es como si a Damaris, ante los actos indisciplinados de Chirli, dejara de importarle y de quererla. Esta crisis llega a uno de sus puntos máximos cuando la perra queda embarazada:

[...] no soportaba verla. Era una tortura encontrarla cada vez más barrigona cuando abría la puerta de la cabaña. Se empeñaba en estar siempre ahí y seguirla de la cabaña al quiosco, del quiosco al lavadero y del lavadero a la cabaña... Damaris trataba de espantarla. "Ándate", le decía, "déjame", y una vez hasta ensayó levantar la mano como si fuera a pegarle, pero ni siquiera se asustó y se mantenía detrás de ella, lenta y pesada por los hijos que llevaba dentro (pp. 75-76).

Esta actitud de Damaris hacia Chirli puede considerarse de dos modos distintos. Si se la lee desde el punto de vista de la madre, la mujer está decepcionada de la hija, que a raíz de su desobediencia ha quedado preñada. Damaris no acepta que Chirli haya crecido y que ya no dependa más de ella. Por otra parte, si se lo ve desde la perspectiva de la mujer (del deseo de ser madre), Damaris experimenta un proceso de envidia, porque Chirli ha logrado lo que ella siempre quiso: quedar embarazada. Por eso el enojo y la "tortura" de verla en su estado gestante. Lo irónico de la situación es que Chirli no resultó ser una buena madre:

La segunda noche se comió a uno de los cachorros y los días que siguieron dejaba abandonados a los tres que quedaron para asolearse en el andén de la piscina o echarse en el lavadero, donde siempre estaba fresco, o debajo de alguna de las casas con los otros perros, en cualquier lado con tal de no estar cerca de ellos. A Damaris le tocaba agarrarla a la fuerza, llevarla de vuelta al quiosco y obligarla a que se quedara acostada para que ellos pudieran mamar (p. 77). 
Tal comportamiento es gravitante en el relato, pues le confirma a Damaris que Chirli no encarna precisamente la hija que tanto deseaba. Lejos de la imagen ideal de la hija tranquila, obediente y sumisa, se obtiene a un ser rebelde, insubordinado, que no escarmienta con ninguna medida. El colmo de esta situación es que Chirli no solo queda embarazada, sino que no se porta como una verdadera madre. No cumple con los mandatos a los que supuestamente está obligada en su nueva condición: ni alimenta ni cuida a sus cachorros. Todo ello hace que la relación entre Damaris y Chirli se deteriore. Por eso la mujer busca deshacerse de su perra, regalándola. Sin embargo, en forma reiterada Chirli huye de su nuevo hogar y retorna a la casa de Damaris. Esta última la regresa por tercera vez consecutiva y le pide a Ximena, la nueva dueña de Chirli, que la ate para que no pueda huir más.

Cuando Damaris cree que todo acabó, a la mañana siguiente se topa con la sorpresa de encontrar a Chirli otra vez en su lugar de siempre, pero con la novedad de que esta ha destrozado unas cortinas muy valiosas para Damaris, las cuales había lavado y colgado la tarde anterior. Eran las cortinas del finado Nicolasito, el niño rico que conoció en su infancia y a quien vio ser arrastrado por el mar en el acantilado, sin que ella pudiera hacer algo para evitarlo. Dámaris siempre cargará con esta culpa. Los padres del niño se fueron del lugar, pero dejaron la casa de verano al cuidado de una persona. Cuando esta última murió, Damaris les prometió por teléfono a los dueños de casa que se haría cargo de su mantenimiento y limpieza, en especial del cuarto de Nicolasito, en el que destacaban unas cortinas con motivos de El libro de la selva. Al ver desgarradas dichas cortinas (había otras en el tendedero, pero estaban intactas), Damaris reaccionó con furia y cogió por el cuello al animal con una soga. En pleno forcejeo, la mujer se dio cuenta de que Chirli estaba embarazada de nuevo:

\begin{abstract}
"Está preñada otra vez", se dijo y siguió apretando con más ganas, apretando, hasta mucho después de que la perra cayó extenuada, se hizo un ovillo en el suelo y dejó de moverse. Un charco amarillo de orina fuerte se esparció lentamente hacia Damaris y se hizo cada vez más largo y delgado hasta que alcanzó sus pies descalzos. Solo entonces Damaris reaccionó. Aflojó la soga, se alejó del charco, se acercó para tocar con un pie a la perra, y como no se movió, tuvo que aceptar lo que había hecho (Quintana, 2019, pp. I00-I0I).
\end{abstract}

Damaris llega al límite. Ante la imposibilidad de soportar la conducta de Chirli, termina ahorcándola. Se trata de una acción violenta, que se agudiza cuando Damaris 
se percata de que la perra está gestando por segunda vez. Este hecho termina por irritar a la mujer y, en consecuencia, jala de la soga con una crueldad inusitada. ¿Cómo puede considerarse este final de Chirli? Una lectura posible apunta a que Damaris, al darse cuenta de que no podía deshacerse de ella regalándola, opta por eliminarla, pero hay que recalcar que esto estaría motivado por la conducta rebelde de Chirli hacia su madre protésica, Damaris. Otra lectura, más inquietante, y que refuerza una impresión que ya se había esbozado líneas atrás, es que esta acción sádica protagonizada por Damaris se explica en el hecho de que Chirli puede procrear (incluso dos veces) y ella no. Se trataría, entonces, de un acto de envidia por aquello que no se puede obtener. Sea cual fuere la explicación, el comportamiento de Damaris puede ser catalogado como el accionar de una mala madre, aunque sea protésica, porque no actúa en función de los roles y mandatos que la sociedad heteropatriarcal establece. Debe señalarse que el miedo que experimenta Damaris ante la posibilidad de que descubran que ha actuado de ese modo, se relaciona con la circunstancia de que su entorno familiar y social ha aceptado a Chirli como su hija. En este sentido, se trata de un acto filicida. Pese a que la víctima es un animal, la trascendencia gravita en el orden simbólico. El destino de Damaris no era el de la maternidad; aun así desafió su designio al adoptar a un animal y convertirlo en un hijo. Su propósito se ve truncado ante el hijo deseado que no está a la altura del deseo. Y sumado a ello, Damaris no está dispuesta a cumplir los mandatos de la maternidad hasta las últimas consecuencias. Si bien en un primer momento se esforzó por adecuarse a estos, lo cierto es que dichos mandatos la han sobrepasado, provocando en ella la emergencia de una violencia de la que no se creía capaz.

Precisamente, la violencia es un elemento fundamental que recorre todo el relato de Pilar Quintana. No solo está representada en el asesinato de Chirli, sino que aparece en una serie de manifestaciones domésticas como el envenenamiento sistemático y reiterado de los perros del pueblo. Ahora bien, un rasgo que llama la atención de esta violencia es que su existencia es de alguna manera negada por los personajes de la diégesis de la novela e incluso por el narrador de esta. Por ejemplo, a pesar de que se trata de una práctica común entre sus vecinos, Damaris se resiste a pensar que mataban a los perros a propósito, cree que estos "se comían por error las carnadas con veneno que dejaban para las ratas o a las ratas que estando envenenadas eran fáciles de cazar”(Quintana, 2019,p. 9). Asimismo, cuando se entera tiempo después de que el perro de Ximena, hermano de Chirli, también 
muere envenenado, supone que "era posible que lo hubiera matado otra cosa, una culebra o una enfermedad, por ejemplo” (p. 45). Como se aprecia, Damaris se niega aceptar la violencia de la gente que la rodea, para ella no existe tal, los sucesos se generan por otras cuestiones en las que no hay dolo alguno de parte de las personas de su comunidad.

Tal actitud no es privativa de Damaris, pues se extrapola al resto de habitantes del pueblo, a quienes, si bien viven en medio de un clima de violencia, pareciera que nos les interesara profundizar en sus causas. Por ejemplo, esto sucede con el ya mencionado envenenamiento de los perros. Nunca se preguntan quién lo hace ni por qué. Solo se produce en forma reiterada, como un evento cotidiano que la gente acepta sin indagar en su posible causa. Lo mismo sucede con la muerte de algunos personajes como el señor Gene, el cuidante de la casa de los Reyes y la madre de Damaris. El primero apareció ahogado un día en el mar. A pesar de que padecía una parálisis casi total del cuerpo y se encontraba postrado en una silla de ruedas, la gente aceptó que se había suicidado, o que su esposa, que sufría de lagunas mentales, lo habría empujado por cansancio o pena. Pero los vecinos no se preguntan más. Sobre el cuidante de la casa de los Reyes, la gente asumió que fue un accidente de caza. Nadie hizo algún comentario extra. Y respecto a la madre de Damaris, se dice que murió como resultado de una bala perdida. Esta vez es el narrador el que luego de mencionarlo decide pasar a otro asunto, sin proporcionar al lector una mínima explicación de tan terrible suceso. Es como si, a pesar de que existen estas manifestaciones de violencia, se prefiriera silenciarlas, negarlas. Solo ocurren y ya. A nadie (incluyendo al narrador) le interesa saber ni decir más de la cuenta, se las acepta como un hecho más de la cotidianidad.

Si bien en La perra no se puede determinar las fechas exactas en las que ocurren los acontecimientos materia de la diégesis, lo cierto es que algunas referencias remiten a la Colombia contemporánea (la mención a celulares, mensajes de textos y demás adminículos modernos lo prueban así). En ocasiones pareciese que la novela habla sobre el posconflicto que vive Colombia, sobre su periodo de paz, y advirtiera que no obstante la violencia a gran escala está desapareciendo, la de escala menor, doméstica, microfísica, aún sigue en pie, instalada en el interior de la gente.

El filósofo Byung-Chul Han (2016) no se equivoca cuando afirma que "Hay cosas que nunca desaparecen. Entre ellas la violencia”(p.13). Ella busca otras maneras de manifestarse que no sean explícitas, se camufla para no ser contrarrestada. En 
la novela de Quintana está interiorizada en los individuos y en la forma en la que aprecian la realidad de su contexto. Para ellos la violencia es invisible, o quiere pasar como tal, no porque no pueda verse, sino porque ya a nadie incomoda o perturba su existencia. Como dice Raymond L. Williams, refiriéndose a la literatura colombiana, "quizá la mayoría [de los libros] han sido vehículos de diálogo ideológico [...] y siempre se han relacionado a la actividad política" (citado en Rutter-Jensen, 2009, p. 37). Esta sentencia puede ser aplicable a La perra, pues además de presentar una reflexión sobre la maternidad, enlaza este problema personal y privado con uno de carácter social y político: la violencia.

\section{Consideraciones finales}

La novela narra la historia de una mujer que, si bien no renuncia a los mandatos de género, intenta adecuarlos a sus circunstancias particulares. En este sentido, adoptar a un perro como si fuera un hijo debe leerse en tanto acto de rebeldía en contra del sistema genérico. Sin embargo, la novela también muestra que estas exigencias de maternidad a las que están sujetas las mujeres conllevan la imposibilidad de su cumplimiento a cabalidad, lo que genera en las madres estados de crisis que pueden derivar en actos plenos de violencia (como la muerte de Chirli). Hay una idea general en torno al amor de las madres hacia sus hijos, pero lo cierto es que se trata de una una cuestión de carácter cultural, más que biológico. La novela de Quintana saca a relucir dicha situación. En este sentido, se debe destacar a La perra dado que devela ese otro lado de la maternidad que la gente se niega a aceptar, un trabajo difícil para el que no todos los seres humanos están capacitados. Asimismo, la novela habla acerca de la integración de la violencia en la vida de las personas, desarrollándose a nivel micro, en lo doméstico, en lo íntimo. De algún modo, el relato se constituye en una especie de aprendizaje de los excesos a los que puede llegar un ser humano cuando está en una posición límite. En este caso, por culpa de los mandatos de la maternidad. Finalmente, se puede decir que La perra de Pilar Quintana se inscribe en lo que sería el subgénero narrativo de las maternidades disidentes, porque pone en escena un nuevo sujeto social: las "malas madres", personajes que empiezan a ser pensados ya no desde los actos que realizan, sino desde las condiciones sociales complejas en las que se desarrollan como individuos. 


\section{Referencias bibliográficas}

Butler, J. (1997). Excerpt from introduction to Bodies that Matter. In R. Lancaster; M. di Leonardo (Eds.). The Gender and Sexuality Reader (pp. 531-542). London: Routlegde.

Donath, O. (2017). Madres arrepentidas. Una mirada radical a la maternidad y sus falacias sociales. Barcelona: Resevoir books.

Garay, R. (2008). El destino de ser madres: la ideología de la maternidad como soporte discursivo de las nuevas tecnologías reproductivas. En M. Tarducci. Maternidades en el siglo XXI (pp. 29-59). Buenos Aires: Espacio.

Han, B. C. (2016). Topología de la violencia. Madrid: Herder.

Ibarlucía, B. (2009). Roles sexuales. En S. B. Gamba (Coord.). Diccionario de estudios de género y feminismos (pp.287-289). Buenos Aires: Biblos.

Lagarde, M. (1997). Género y feminismo. Desarrollo humano y democracia. Madrid: horas y HORAS.

Ledezma, A. (2016). ¿Nombrarse o ser nombrado? El nombre como depositación. Revista Wimblu 11 (2), pp. 31-39.

Marcer, R; Kicillof, D. (1990). Introducción al psicoanálisis de la elección de los nombres propios: el caso de Sigismund Schlomo Freud. Revista de Psicoanálisis 47 (1), pp. 129-139.

Ortner, S. (1979). ¿Es la mujer con respecto al hombre lo que la naturaleza con respecto a la cultura? En O. Harris y K. Young (Eds.). Antropología y feminismo (pp. 109-131). Barcelona: Editorial Anagrama.

Palomar, C. (2004). Malas Madres: la construcción social de la maternidad. Debate Feminista 30, pp. 12-34.

Quintana, P. (2019). La perra. Barcelona: Penguin Random House.

Recalcati, M. (2018). Las manos de la madre. Deseo, fantasmas y herencia de lo materno. Barcelona: Anagrama.

Reyes, M. (2017). La representación de la maternidad en la literatura italiana. El caso de Juana I, Semíramis y Erzsebet Bathory. Tonos digitales: Revista de Estudios Filológicos 32, pp. 1-16.

Rich, A. (2019). Nacemos de mujer. La maternidad como experiencia e institución. Madrid: Traficantes de Sueños.

Rose, J. (2018). Madres. Un ensayo sobre la crueldad y el amor. Madrid: Siruela.

Rutter-Jensen, C. (2009). La heteronormatividad y sus discordias. Narrativas alternativas del afecto en Colombia. Bogotá: Universidad de los Andes.

Sen, A. (1985). Well-being, Agency and Freedom: The Dewey Lectures 1984. The Journal of Philosophy 82 (4), pp. 169-221. 